\title{
Utilization of Cloud Computing in Economics Education and Health Economics: A Valuable Resource
}

\author{
Sylvester N. Ogbueghu ${ }^{1}$, Anuli Regina Ogbuagu ${ }^{2}$, Amos Nnaemeka Amedu ${ }^{1}$, Daniel Munachiso Eze ${ }^{1}$, \\ Augustine Igwe Robert ${ }^{3}$, Ifeoma Euphemia Opara ${ }^{4}$, Benedict Ejiofor Ugwuanyi ${ }^{1}$, \\ Chukwuma Ogbonnaya Chukwu ${ }^{5} \&$ Lazarus Bassey Abonor ${ }^{6}$ \\ ${ }^{1}$ Department of Social Science Education, University of Nigeria, Nsukka, Enugu State, Nigeria \\ ${ }^{2}$ Department of Economics and Development Studies, Alex Ekwueme Federal University Ndufu-Alike Ikwo, \\ Ebonyi State, Nigeria \\ ${ }^{3}$ Department of Social Science Education, University of Calabar, Cross River State, Nigeria \\ ${ }^{4}$ Department of Economics, FCT College of Education, Zuba, Abuja, Nigeria \\ ${ }^{5}$ Department of Arts and Social Science Education, Ebonyi State University, Abakaliki, Ebonyi State, Nigeria \\ ${ }^{6}$ Department of Social Work, University of Calabar, Cross River State, Nigeria \\ Correspondence: Daniel Munachiso Eze, Department of Social Science Education, University of Nigeria, Nsukka, \\ Enugu State, Nigeria. E-mail: munachiso.eze@unn.edu.ng
}

Received: December 11, 2019 Accepted: March 20, 2020 Online Published: May 8, 2020

doi:10.5539/gjhs.v12n5p117 URL: https://doi.org/10.5539/gjhs.v12n5p117

\begin{abstract}
This paper examines the use of cloud computing as a tool in economics education and analysis of performance in health economics. The paper methodology was documentary analysis. Three independent experts assisted in the extraction of information used in this research paper. Results indicate a growing need to advance the economic utility of cloud computing as a technological tool in economics education and analysis of economic performance in health economics. Empirical studies are required to corroborate the extent to which cloud computing is being utilized as a technological tool in several institutions and organizations for analysis of economic performance and educational purposes.
\end{abstract}

Keywords: Cloud computing, economics education, economic performance, technological tool

\section{Introduction}

Cloud computing can be defined as a subscription-based technology where network storage can be obtained as well as the resources of the computing system. The most vital form of thinking on cloud computing is to consider and understand one's experience with email (Groom, 2018). Cloud computing represents one of the most important shifts in information technology which we likely see in our life and daily endeavours (Cloud Security Alliance, 2010). Cloud computing is not a new technology but a new way of delivering computing resources. It is a style of computing over the internet (Chawla \& Diwaker, 2012). It is the latest way of delivering things on the Internet. Understanding the economic impact of cloud computing could enable firms to rent computing power and storage from service providers and to pay on demand, with a significant impact on the cost structure of industries, turning some of the fixed costs into marginal costs of production (Etro, 2014). The diffusion of cloud computing on market structures and competition could exert a significant influence on incentives to build new business, investments and macroeconomic growth, job creation in all industries, job reallocation in the information and communications technology sector, and public finance accounts (Etro, 2014). Public finance economists who have focused on studying the finance of schools (Hanushek, 2015) can explore the benefits of cloud computing. Economics is seen as "the study of how people, businesses, societies, or nations deal with scarcity" (Economic Theory Analysis Project 1). Economics studies the choices we make as individuals and how those choices shape our economy. Education economics is the study of economic problems related to education, including education production, funding and education supply, and the comparative utility of different educational systems and policies. Economics education is an academic discipline that reflects on two major themes: the existing state of economics instruction, textbooks and pedagogical methods used to teach economics at all educational levels and attempts to enhance it; and study into the usefulness of alternate teaching strategies in economics, the degree of academic 
awareness in various classes and the causes in economics. Economics education can be seen as a method, research and commodity. It is a cycle involving a period of inculcating the requisite skills and values on the learners, in other words, it involves training the learners to become the teachers and disseminating useful economic knowledge on the learners in others to boost their living conditions through engaging in practical undertakings. It is a body of standardized information that is subject to empirical evidence/test; and as a result, economics education entails inculcating saleable values/skills/dispositions on learners that are suitable for labour employers and society as a whole. Proper analysis of economic performance using cloud computing can provide a better comprehension of a nation's economic development. This is so because it may aid transparency and understanding of a nation's GNP (Manqele, 2019). Therefore, the objective of this paper is to examine the use of cloud computing as a technological tool in economics education and analysis of economic performance in health economics.

\section{Method}

The paper methodology was documentary analysis. Google search engine and Google scholar were used to source for relevant information with keywords like cloud computing, cloud computing as a technological tool, economics education, use of cloud computing in economics, and analysis of economic performance using cloud computing. Three independent experts assisted in the extraction of information used in this research paper.

\section{Results}

Because of the current financial crisis and rising needs, highlighting the relevance of cloud computing in economics and economics education becomes necessary. Institutes of Higher Education (HE) face difficulties in having the requisite IT support for educational, research and development activities. The Cloud Computing (CC) ecosystem will help rescue HE institutes from the challenges. The HE Institutes will take advantage of CC's opportunities whilst mitigating the related security threats to provide access to advanced IT networks, data centers, and software, and to secure sensitive data. Cloud Computing is a new paradigm of computing infrastructure provision which promises to achieve a vision of computer utilities. The most active research topic in Cloud Computing is its economic aspect. Yeoet, al cited in (Andročec, 2011) states that cloud computing promises reliable services delivered through new virtualized data centers and it achieves a 21 st century vision of computer utilities. In Durkee cited in (Andročec, 2011), cloud computing address these needs with, on-demand access, elasticity, pay-per-use, connectivity, resource pooling and abstracted infrastructure.

The relevance of cloud computing in the analysis of economic performance becomes paramount for economists. From a business perspective, cloud computing has revolutionized the information and communication technology industry by offering scalable and on-demand ICT services as well as innovative pricing plans such as pay-per-use and subscription (Wu, Terpenny, \& Gentzsch, 2015). Considering the economic benefits of cloud computing, cloud-based design and manufacturing has been proposed as a new paradigm in digital manufacturing and design innovation (Wu, Terpenny, \& Gentzsch, 2015). In using cloud computing as a technological tool in economics education and analysis of economic performance, it can improve automation, result in fewer human errors, more reliable ICT infrastructure prompting lower risks, and operating costs (Economic Theory Analysis Project 1). Cloud computing has outsourcing tactics, has shaped the American economy for some time by impacting how organizations are running their operations, and with the proliferation of cloud computing, some organizations start in-sourcing back their it and enhance it with cloud computing, cited in (Economic Theory Analysis Project 1).

More so, cloud computing technology and computer clusters provide educational services on a real scenario in which a standard university IT infrastructure is moved into cloud (Boja, Pocatilu, \& Toma, 2013). In recent time, studies found that the development of information and communication technologies, the formation of global computer networks has resulted in the creation of new innovative ways of growth, in particular, the implementation of cloud computing, which have been applied in all spheres of economy and business (Bataev, 2017). In some studies, the use of cloud services are analyzed; forms of cloud computing's representation are considered; the estimation of financial indicators of the world cloud computing market is given; and particular attention is paid to the prospects of introducing cloud services in education (Bataev, 2017).

Recent studies show that, cloud computing provides a way for business to manage its computing resources online (Sahu, 2013). The term has evolved over recent years and can be used to describe the use of a third party for storage and computing needs as it allows businesses to access information virtually, creating a flexible and global way of accessing data any place, any time (Sahu, 2013). It enables all businesses to get the best of technology at economical costs. While a lot of research is currently taking place in the technology itself, there is an equally urgent need for understanding the business-related issues surrounding cloud computing (Sahu, 2013). Also, there is need to use of cloud computing as a technological tool in economics education and analysis of economic performance. A business perspective asserts that cloud computing has revolutionized the information and 
communication technology industry by offering scalable and on-demand ICT services as well as innovative pricing plans such as pay-per-use and subscription (Wu, Terpenny, \& Gentzsch, 2015). Linthicum cited in Andročec (2011), presented many dimensions of the Cloud Computing value such as an ongoing operational cost reduction, capital preserving, value of upsizing and downsizing on demand, shifting the risk, agility and reuse. In the same vein, the use of cloud computing in the analysis of economic performance involves the cost/benefit methodology that is composed of eight steps: understand the existing issues, assign costs, model "as is", model "to be", define value points, define hard benefits, define soft benefits, and create final business case. Dash, et al., cited in Andročec (2011), proposed an economic model for a cloud cache suitable for the querying service of large scientific datasets. It is based on a cost model that takes into account network bandwidth, disk space and CPU time. Hosseini sees the probable challenges with the use of cloud computing in economics and economics education from an organizational perspective. The vast majority of current work on cloud costs is simplistic from an enterprise perspective. The economic issues around application migration and existing procurement policies are not considered. The true costs of using cloud computing services in a specific organization with the help of tools and techniques are still very important challenges.

\section{Conclusion}

There is a growing need to advance the economic utility of cloud computing as a technological tool in economics education and analysis of economic performance. Thus, this paper examined the application of the use of cloud computing as a technological tool in economics education and analysis of economic performance. Our findings indicate a growing need to advance the economic utility of cloud computing as a technological tool in economics education and analysis of economic performance. Empirical studies thus are required to corroborate the extent to which cloud computing is being utilized as a technological tool in several institutions and organizations for analysis of economic performance and educational purposes.

\section{Competing Interests Statement}

The authors declare that there are no competing or potential conflicts of interest.

\section{References}

Andročec, D. (2011). Research Challenges for Cloud Computing Economics. 22nd Cent EurConf Inf.

Bataev, A. V. (2017). Cloud technology as innovative way in engineering and economic education. Proceedings of the 2017 International Conference "Quality Management, Transport and Information Security, Information Technologies", IT and QM and IS 2017. https://doi.org/10.1109/ITMQIS.2017.8085904

Boja, C., Pocatilu, P., \& Toma, C. (2013). The Economics of Cloud Computing on Educational Services.Procedia - SocBehav Sci., 2013. https://doi.org/10.1016/j.sbspro.2013.09.328

Chawla, S., \& Diwaker, C. (2012). Cloud computing. Int J Appl Eng Res., 2012. https://doi.org/10.4018/jeei.2012040104

Cloud Security Alliance. (2010).Top Threats to Cloud Computing. Security.

Economic Theory Analysis Project (1).

Etro, F. (2014). The economics of cloud computing. In: Cloud Technology: Concepts, Methodologies, Tools, and Applications. https://doi.org/10.4018/978-1-4666-6539-2.ch101

Groom, F. M. (2018). The Basics of Cloud Computing. Enterp Cloud Comput Non-Eng, 1-42. https://doi.org/10.1201/9781351049221-1

Hanushek, E. A. (2015). Economics of Education. In International Encyclopedia of the Social \& Behavioral Sciences (2nd ed.). https://doi.org/10.1016/B978-0-08-097086-8.92052-X

Manqele, S. (2019). POLICY BRIEF: The Analysis of Economic Development Author: SbonisoManqele University of Kwa-Zulu Natal (UKZN).

Sahu, R. (2013). Cloud Computing: An Innovative Tool for Library Services. Natl. Conf. Libr. Inf. Sci. Inf. Technol. Educ., 2013.

Wu, D., Terpenny, J., \& Gentzsch, W. (2015). Cloud-Based Design, Engineering Analysis, and Manufacturing: A Cost-Benefit Analysis. Procedia Manufacturing. https://doi.org/10.1016/j.promfg.2015.09.061 


\section{Copyrights}

Copyright for this article is retained by the author(s), with first publication rights granted to the journal.

This is an open-access article distributed under the terms and conditions of the Creative Commons Attribution license (http://creativecommons.org/licenses/by/4.0/). 